\title{
A AFETIVIDADE COMO INSTRUMENTO DE APRENDIZAGEM E COMO FACILITADOR DA RELAÇÃO PROFESSOR/ALUNO NA EDUCAÇÃO INFANTIL
}

\author{
Erineia Martins Valadares Bittencourt ${ }^{1}$ \\ Herica Santos Molon ${ }^{2}$
}

\begin{abstract}
Resumo
Este artigo tem como finalidade abordar a afetividade como instrumento de suma importância na construção do processo de ensino-aprendizagem no contexto da educação infantil, e como esse processo pode trazer experiências marcantes na relação professor aluno dentro das salas de aula. Nas últimas décadas temos problemas diversos que tem contribuído para a banalização da educação e dos valores a ela agregados, tais como: desestruturação das famílias, políticas públicas insuficientes, desvalorização profissional, jornadas duplas, falta de motivação dos profissionais e dos alunos que não consideram a escola atrativa, alunos sem perspectivas futuras pela ausência familiar, etc. A consequência é visível, pois temos crianças que passam pela educação infantil sem agregar conhecimento a sua vida. De forma que se torna vital, assim, compreender a importância de um ambiente propício ao exercício da afetividade na vida desses alunos e um ambiente onde as relações interpessoais entre o educador/aluno/família, seja uma constante para um desenvolvimento psicológico, cognitivo e social satisfatório para o aluno.
\end{abstract}

\section{Palavras-Chave: Afetividade. Aprendizagem. Relacionamento.}

\section{INTRODUÇÃO}

A afetividade quando abordada como processo indispensável na construção da estrutura emocional, psicológica e cognitiva da criança, ainda causa estranheza no ambiente educacional, e por vezes é apontada como responsabilidade exclusiva da família. Mas quando nos aprofundamos no assunto e buscamos respaldo em pesquisas, livros, artigos e grandes escritores, vemos que o processo ensino/aprendizagem começa sempre pelo relacionamento professor/aluno, pela construção de uma rotina de confiança, empatia e valorização pessoal, segundo francês Henri Wallon (1879-1962): ao estudar a criança, ele não coloca a inteligência como o principal componente do desenvolvimento, mas defende que a vida psíquica é formada por três dimensões - motora, afetiva e cognitiva -, que coexistem e atuam de forma integrada.

\footnotetext{
${ }^{1}$ Mestranda do Curso de Ciências da Educação. E-mail: erineia.valadares@ hotmail.com

${ }^{2}$ Mestranda do Curso de Ciências da Educação. E-mail: hericasmolon@ hotmail.com
} 
"O que é conquistado em um plano atinge o outro mesmo que não se tenha consciência disso", diz Laurinda Ramalho de Almeida, vice coordenadora do Programa de Estudos Pós-Graduados em Educação, da PUC-SP. Nesse artigo, baseado em pesquisa bibliográfica e exploratória, a afetividade será analisada no âmbito estritamente pedagógico e como instrumento nec essário ao ensino/aprendizagem a começar na Educação.

A afetividade é considerada por diversos estudiosos como fundamental na construção de um ambiente propício para que o processo ensino/aprendizagem aconteça de forma natural e no tempo devido, (Espinosa, 2002; Dantas, 1992; Snyders, 1993; Freire 1994) entre outros, nos fornecem dados que não deixam dúvidas da necessidade do professor em seu ambiente de trabalho, transformar sua rotina em um tempo precioso de interação e muito aprendizado.

\begin{abstract}
A afetividade se constitui como uma das habilidades que as profissionais de Educação Infantil Precisam utilizar para elaboração das propostas pedagógicas, no planejamento das atividades e na mediação das relações entre professora-criança, entre criançacriança e entre as crianças e os objetos de conhecimento. Dessa forma, a dimensão afetiva é inerente à função primordial das creches e pré-escolas, cuidar e educar (CACHEFFO e GARMS, 2015, p. 25).
\end{abstract}

Nessa perspectiva alguns teóricos colaboram em suas pesquisas e trabalhos em como essas relações de afetividade transformam e interferem no processo de ensino e aprendizagem no contexto escolar e de como essa afetividade é essencial no desenvolvimento infantil, tornando prazeroso o fazer diário do profissional envolvido.

O professor da Educação Infantil precisa ter o conhecimento sobre afetividade além das práticas desenvolvidas em sala de aula, ofertando ao aluno o ambiente e acolhimento que o mesmo precisa. Essas boas práticas ofertadas e vivenciadas em sala de aula, podem modificar toda vivência da criança em todo seu cenário cultural, legitimando a necessidade que a criança precisa e que muitas vezes lhe é negada.

A desigualdade social, ausência e desestrutura da família vem aumentando cada vez mais na sociedade, parte dessas crianças estão em situações de muita carência, e chegam na escola para ter alguma refeição e aconchego, e se distanciar da sua realidade. O papel de facilitador faz com que o professor consiga notar e atuar na dura realidade que algumas crianças estão inseridas, auxiliando na formação de um sujeito social, ao invés de um mero transmissor de conteúdo.

A criança como todo ser humano, é um sujeito social e histórico e faz parte de uma organização familiar que está inserida em uma sociedade, com uma determinada cultura, em um determinado 
momento histórico, é profundamente marcada pelo meio social em que se desenvolve, mas também a marca. A criança tem na família, biológica ou não, um ponto de referência fundamental, apesar da multiplicidade de interações sociais que estabelece com outras instituições sociais. (RCNEI, p.21).

O processo da afetividade no ensino engloba todas as crianças e através da afetividade o professor irá encontrar o caminho para conduzir cada criança pela sua particularidade e não haverá exclusão de aluno por conta de ser diferente, conseguindo assim alcançar o crescimento que a criança necessita e auxiliando em todos os aspectos da vida, conseguindo realizar seus objetivos de forma clara.

Os autores Leite e Tassoni, 2000, p. 9-10, afirmam:

[...] a presença continua da afetividade nas interações sociais, além da sua influência também contínua nos processos de desenvolvimento cognitivo. Nesse sentido, podese se pressupor que a interação que ocorre no contexto escolar também é marcada pela afetividade em todos s seus aspectos. Pode-se supor, também, que a afetividade se constrói como um fator de grande importância na determinação da natureza das relações que se estabelecem entre os sujeitos (alunos) e os diversos objetos do conhecimento (áreas e conteúdos escolares), bem como na disposição dos alunos diante das atividades propostas e desenvolvidas.

Nesse contexto vamos buscar compreender a influência da afetividade no processo de aprendizagem dos alunos da Educação Infantil, analisando como a afetividade ajuda no processo de aprendizado da criança e como o professor, sendo facilitador, pode influenciar o aluno auxiliando na construção como sujeito social.

\section{AFETIVIDADE E SEUS CONCEITOS}

A afetividade é um estado psicológico do ser humano que pode ou não ser modificado a partir de situações, é um estado de grande influência no comportamento e aprendizado junto com o desenvolvimento cognitivo, e também está diretamente ligada à formação do caráter de um determinado indivíduo. Os sentimentos afetivos exercem um importantíssimo papel durante toda a vida, mas principalmente quando criança, fase em que se concentra todo processo de aprendizagem das pessoas podendo ser definida em diferentes perspectivas, neste trabalho iremos abordar a afetividade na perspectiva da pedagogia, considerando as emoções que são expressões da vida afetiva e são acompanhadas de reações e sentimentos. 
Se procurado no dicionário Aurélio (1994), afetividade está definida como: “Conjuntos de fenômenos sobre a forma de emoções, sentimentos e paixões, acompanhados sempre dá impressão de dor ou prazer, de satisfação ou insatisfação, de agrado ou desagrado de alegria ou tristeza". Ainda de acordo com o Dicionário de Filosofia de Nicola Abbagnano, a palavra afetividade designa o conjunto de atos como bondade, inclinação, devoção, proteção, apego, gratidão, em resumo, pode ser caracterizada sob a importância que uma pessoa dá a outra, cuidando, zelando, protegendo e porque não dizer, ensinando.

Dantas (1990, p.10) conceitua afetividade da seguinte maneira: "afetividade designa [...] os processos psíquicos que acompanham as manifestações orgânicas da emoção. A afetividade pode bem ser conceituada como uma das formas de amor”. Almeida e Mahoney $(2007$, p.17) definem afetividade como: "capacidade, disposição do ser humano de ser afetado pelo mundo externo e interno por meio de sensações ligadas a tonalidades agradáveis ou desagradáveis. Podemos então relacionar afetividade com aspectos sociais de acordo com Engelmann (1978, p.130,131).

[...] parece mais adequado entender o afetivo como uma qualidade das relações humanas e das experiências que elas evocam (...). São as relações sociais, com efeito, as que marcam a vida humana, conferindo ao conjunto da realidade que forma seu contexto (coisas, lugares, situações, etc.) um sentido afetivo.

Com o auxílio da afetividade, professores e alunos conseguem criar laços entre eles, Henri Wallon (1954, p.288), psicólogo francês, tem o seguinte pensamento sobre o conceito de afetividade:

\begin{abstract}
A afetividade é um domínio funcional, cujo desenvolvimento dependente da ação de dois fatores: o orgânico e o social. Entre esses dois fatores existe uma relação recíproca que impede qualquer tipo de determinação no desenvolvimento humano, tanto que a constituição biológica da criança ao nascer não será a lei única do seu futuro destino. Os seus efeitos podem ser amplamente transformados pelas circunstâncias sociais da sua existência onde a escolha individual não está ausente.
\end{abstract}

A evolução de uma criança não depende somente da capacidade intelectual, ela é fruto do ambiente social no qual está inserida, permitindo ou impedindo que potencialidades sejam desenvolvidas. A ausência ou pouco afeto durante a vida de um indivíduo pode trazer inúmeros transtornos, como por exemplo fazer com que o adulto seja mais propenso a desenvolver medos, depressão e ansiedade. É algo que deve estar presente no ambiente em que o educando está inserido no seu cotidiano, inclusive e especialmente em sala de aula, sendo o professor o modelo para o aluno se espelhar, observando e aprendendo atitudes como paciência, dedicação, amizade, companheirismo, valorização pessoal, desenvolvendo assim um indivíduo social. 
Então, a construção de laços afetivos é extremamente importante para a vida como um todo. Crescer sem apropriar-se dessa ferramenta poderosa de "ações e reações", pode transformar o indivíduo em um ser possuidor de lembranças e recordações ruins, numa pessoa apática e exclusa de uma vida social saudável.

As atividades planejadas e desenvolvidas em sala de aula precisam estar alinhadas com a trabalho de envolver e desenvolver pedagógico/afetivo, pois os mesmos possuem influência no quesito aprendizagem e desenvolvimento dos alunos, a maneira como o professor aplica o conteúdo, pode afetar cada aluno de maneira particular, por isso a prática deve se basear em aulas participativas, lúdicas, dinâmicas, desenvolvendo atividades que se utilizam da imaginação e espontaneidade de cada educando.

A afetividade na Educação Infantil possibilita o ensino ir além do tradicional, buscando relações concretas com os alunos, auxiliando no diagnóstico que norteia o professor a diferenças individuais e comportamentais, podendo assim fazer num trabalho com resultados mais promissores.

Dessa forma a afetividade é de grande importância para a educação, pois a partir dela podemos desenvolver sujeitos que desempenham deveres e também os respeita e representa, sujeitos críticos, com opiniões próprias e responsáveis por seus atos.

\section{APRENDIZAGEM A PARTIR DA AFETIVIDADE}

Na educação infantil, trabalhamos com crianças nos seus primeiros anos de vida onde toda sua estrutura emocional, física, psíquica está sendo formada, e onde o aprendizado precisa ser estimulado de forma a construir um ambiente saudável e propicio para o educando. Nós enquanto educadores, cabe mediar esse processo de forma a transformar vidas através do nosso fazer diário.

A afetividade na Educação Infantil possibilita o ensino ir além do tradicional, buscando relações concretas com os alunos, auxiliando no diagnóstico que norteia o professor a diferenças individuais e comportamentais, podendo assim fazer um trabalho com resultados mais promissores. 
As atividades planejadas e desenvolvidas em sala de aula precisam estar alinhadas com a trabalho de envolver e desenvolver pedagógico/afetivo, pois os mesmos possuem influência no quesito aprendizagem e desenvolvimento dos alunos, a maneira como o professor aplica o conteúdo, pode afetar cada aluno de maneira particular, por isso a prática deve se basear em aulas participativas, lúdicas, dinâmicas, desenvolvendo atividades que se utilizam da imaginação e espontaneidade de cada educando.

Segundo Piaget (1976, p. 16) o afeto é essencial para o raciocínio e o desenvolvimento da inteligência:

[...] vida afetiva e vida cognitiva são inseparáveis, embora distintas. E são inseparáveis porque todo intercâmbio com o meio pressupõe ao mesmo tempo estruturação e valorização. Assim é que não se poderia raciocinar, inclusive em matemática, sem vivenciar certos sentimentos, e que, por outro lado, não existem afeições sem um mínimo de compreensão.

De outro modo, Freire (1996, p. 96) enfatiza as características do professor que envolve afetivamente seus alunos, afirmando que:

O bom professor é o que consegue, enquanto fala trazer o aluno até a intimidade do movimento do seu pensamento. Sua aula é assim um desafio e não uma cantiga de ninar. Seus alunos cansam, não dormem. Cansam porque acompanham as idas e vindas de seu pensamento, surpreendem suas pausas, suas dúvidas, suas incertezas.

Portanto, fica claro que quando o professor desenvolve afetividade para com as crianças, tudo se torna mais fácil. Tanto a aprendizagem quanto a disciplina melhoram se o professor tiver um bom vínculo afetivo com a turma.

Trazendo o aspecto social para interior das nossas escolas, fica claro que a criança está em processo de construção pessoal, social, psíquico e as experiências diárias vivenciadas no contexto escolar vão influenciar e muito na qualidade de sua vida futura. Rousseau afirma que, a criança deveria viver cada fase da infância plenamente, porque, segundo ele, até os 12 anos o ser humano é apenas emoção e corpo, estando a razão ainda em formação. Afirma ainda, o indivíduo viveria em liberdade, não desenfreada, mas no sentido de uma dependência em relação à oposição suscitada pelos adultos. Rousseau afirmava que o verdadeiro objetivo da educação era ensinar a criança a exercer a liberdade. $\mathrm{O}$ aluno somente entraria na sociedade, quando a tendência para a socialização nele surgisse naturalmente após o desenvolvimento da razão; conforme Rousseau: "Viver é o que eu desejo ensinar-lhe. Quando sair das minhas mãos, ele não será magistrado, soldado ou sacerdote, ele será, antes de tudo, um homem" (ROUSSEAU apud GADOTTI, 2006, p. 137). 
Rousseau deixava claro sua aversão à atitude de imposição de professores, que davam aulas com severidade, pois isto contribuiria para a formação de homens rigorosos e rudes. Tinha convicção, que os professores devessem ser mais leves, divertidos com seus alunos, propondo atividades que os motivassem e incentivassem sua curiosidade. Rousseau (1994, p.23) chega a afirmar, assim, que "o aluno deve sobretudo ser amado [...]".

A construção do conhecimento é feita ou deveria, de forma que os alunos descubram a aprendizagem por seu próprio interesse, e pela motivação de um professor afetivo. Rousseau via a infância como parte essencial à formação do indivíduo. Segundo ele, seria preciso levar em conta as características e vivência pessoais de cada criança. Afirma, ainda, que um bom professor observa seus alunos, afim de identificar as suas peculiaridades, necessidades e trabalhá-las. Cerizara (1990, p.108) complementa esta ideia, quando ressalta a importância do que o professor observa a este respeito, “ [...] numa tentativa pedagógica de harmonizar a especificidade da criança com as influências do meio, com as generalidades do desenvolvimento humano" (1990, p.108).

Segundo Cerizara (1990, p.166), a educação deve ter como objetivo o encaminhamento do indivíduo, de forma que ele esteja preparado para viver em uma nova sociedade, enfrentando a realidade e utilizando sensatamente tanto a razão quanto o sentimento, sempre respeitando seu próximo. Visto que o professor é uma das figuras mais importantes da vida do indivíduo, pois é com ele que a criança tem suas primeiras noções de independência e autonomia, seria ele o principal agente desta transformação.

\section{CONSIDERAÇÕES FINAIS}

Abordando o tema afetividade na educação infantil, a pesquisa se propõe a mostrar o quanto é importante e o quanto influencia a afetividade para o desenvolvimento do ser humano, e principalmente no contexto da educação infantil. Após a pesquisa, a seleção de informações e as abordagens do conteúdo, ficou ainda mais claro que a escola além de suas inúmeras responsabilidades no papel fundamental no ensino aprendizagem, também forma cidadãos, 
sendo principal propulsora da cidadania. E juntamente com a família é responsável pela formação de caráter e valores das crianças.

É no interior da escola que as crianças começam a desenvolver relações de amizades, interação e desenvolvimento em que entram em contato com várias realidades e situações distintas ao mesmo tempo, que impulsionam as ações e escolhas da criança. Merece destaque as palavras de Luckesi (1984, p. 213), que esclarece que "o desenvolvimento do educando pressupõe o desenvolvimento de diversas facetas do ser humano: a cognição, a afetividade, a psicomotricidade e o modo de viver. Educação tem que ser não o que pensar, mas sim como pensar". Para isso o professor precisa estar em sintonia as ações que envolvem seu "eu", sua afetividade e o cognitivo precisam estar amadurecidos e preparados para enfrentar tais situações. É preciso que os conteúdos estejam elencados aos valores que são originários da sociedade em que o aluno está inserido para efetivar mudanças no âmbito familiar, escolar e social. Porém, as mudanças só ocorreram se houver um envolvimento, um relacionamento de confiança do aluno para a causa em questão e isto só se dá por meio da afetividade. É vital ser reconhecido como pessoa, cidadão do mundo, valorizado e neste processo, a convivência com o outro, pessoas adultas (professores e funcionários) e conhecimentos do mundo ao seu redor são fundamentais, pois sustentam a base para as relações pessoais e intrapessoais quando adulto e inserido na sociedade.

\section{REFERÊNCIAS:}

BRASIL. Lei no. 9.394/96: Estabelece as Diretrizes e Bases da Educação Nacional. Brasília, 1996. Disponível em: Acesso em: 10 abr. 2018

CERIZARA, Ana Beatriz. Rousseau: a educação na infância. São Paulo: Scipione, 1990.

FERREIRA, A. B. H. Novo Aurélio XXI: o dicionário da Língua Portuguesa. 3 eds. Rio de Janeiro: Nova Fronteira, 1975.

FREIRE, P. Professora sim, tia não: cartas a quem ousa ensinar. São Paulo: Olho D’Água, 1997.

Pedagogia da autonomia: saberes necessários à prática educativa. São Paulo:

Editora Paz e Terra, 1996.

PIAGET, Jean. Psicologia e Pedagogia. Rio de Janeiro: Forense Universitária, 1985. 
ROUSSEAU, Jean Jacques. Projeto para a educação do Senhor de Sainte-Marie

WALLON, H. A evolução psicológica da criança. 2 ed. Lisboa: Edições 70, 1995 Afetividade e aprendizagem - Contribuições de Henry Wallon. São Paulo: Edições Loyola, 2007 A evolução psicológica da criança. Lisboa: Edições 70, 1999. 